\title{
Cortical columns (barrels) display normal size in the brain's primary somatosensory cortex of mice carrying null mutations of the insulin receptor substrate 1 gene: A preliminary report
}

\author{
Marta López-Santibáñez Guevara1, Eileen Uribe-Querol ${ }^{2}$, Alma Lilia Fuentes Farías ${ }^{3 *}$, \\ Esperanza Meléndez-Herrera ${ }^{3}$, Agustine Joseph D’Ercole ${ }^{4}$, Gabriel Gutiérrez-Ospina ${ }^{1,5 *}$ \\ ${ }^{1}$ Departamento de Biología Celular y Fisiología, Instituto de Investigaciones Biomédicas, Universidad Nacional Autónoma de \\ México, México D.F., México \\ ${ }^{2}$ División de Estudios de Posgrado e Investigación, Facultad de Odontología, Universidad Nacional Autónoma de México, México \\ D.F., México \\ ${ }^{3}$ Departamento de Zoología, Instituto de Investigaciones sobre los Recursos Naturales, Universidad Michoacana de San Nicolás de \\ Hidalgo, Morelia, México \\ ${ }^{4}$ Department of Pediatrics, The University of North Carolina at Chapel Hill, Chapel Hill, USA \\ ${ }^{5}$ Coordinación de Psicofisiología, Facultad de Psicología, Universidad Nacional Autónoma de México, México D.F., México \\ Email: ${ }^{*}$ afuentes@umich.mx, gabo@biomedicas.unam.mx
}

Received 10 August 2013; revised 10 September 2013; accepted 25 September 2013

Copyright (C 2013 Marta López-Santibáñez Guevara et al. This is an open access article distributed under the Creative Commons Attribution License, which permits unrestricted use, distribution, and reproduction in any medium, provided the original work is properly cited.

\begin{abstract}
Circuits in barrels of the rodent brain's primary somatosensory (S1) cortex build up following constructivist rules. Previous evidence in mice supports that the precise addition of barrel neuropil is promoted by insulin-like growth factor-1 (IGF-1). The signaling cascades mediating this response remain undetermined. To address whether the effects of IGF1 upon the growth of S1 circuits are mediated by insulin receptor substrate-1 (IRS-1), we studied barrel size in adult mice having the IRS-1 gene knocked out (IRS-1 ko). Our results reveal that barrel size is similar between wild type and IRS-1 ko mice suggesting that IRS-1 is not essential for barrel circuitry growth. Hence, investigations aimed at exploring other substrates activated by IGF-1, namely IRS-2 and IRS-4, are needed to reveal signaling pathways that mediate the precise addition of S1 neuronal circuitry.
\end{abstract}

Keywords: Barrel Cortex; Neuronal Circuit Assemblage; Trophic Interactions; Constructivism

\section{INTRODUCTION}

Conventional wisdom claims that mature neuronal circuits arise from an initially redundant set of connections

${ }^{*}$ Corresponding authors. which are later refined through a process of selective pruning driven by neuronal activity and competition [1-4]. Empirical evidence suggests, however, that this principle is far from universal since circuits in the spinal cord $[5,6]$, the olfactory bulb $[7,8]$ and in the primary visual [9] and somatosensory (S1) [10-13] cortices of different mammals (however, see [14]), are predominantly elaborated by adding up connections and neuronal processes [15].

The cerebral cortex is formed by columns that run vertically through its entire thickness. In S1, these columns are called barrels and they represent collections of mechanosensory receptors distributed throughout the body. In previous reports, we confirmed that barrel neuropil and synaptic contacts are added through postnatal development. More importantly, the addition of barrel neuropil/synapses depended upon the availability of insulinlike growth factor-1 (IGF-1). Indeed, barrels in transgenic mice overexpressing IGF-1 were enlarged, whereas those in transgenic mice having brain ectopic expression of IGF-binding-protein-1 displayed reduced size [16]. Both enlarged and small sized barrels had similar synapse density [17]. These results thus support the concept that neuronal circuits are elaborated by the precise, differential addition of new elements through non-competitive, constructive processes that depend upon the availability of neurotrophic factors (see [11] and [18] for a 
similar conclusion).

Considerable research has been conducted to understand the cellular and molecular mechanisms that underlie the competitive and selective pruning of neuronal connections. However, much less is known about the molecular underpinnings supporting the formation and growth of neuronal connections through constructivist processes. Although molecules governing axonal and dendritic navigation and growth may readily explain precise targeting and directed growth [19], the molecular underpinnings that promote the precise addition of neuronal circuits remain unexplored. Given that IGF-1 overexpression promotes this process in S1 barrels, it is possible that molecules along the IGF-1 signaling pathway may well underlie constructivist events during S1 assemblage.

IGF-1 binds to the IGF receptor type 1 that, after activation, phosphorylates signaling proteins of the insulin receptor substrate (IRS) family. IRSs, in turn, activate effector proteins containing Src homology 2 domains, a process that activates downstream MAP Kinase and the phosphatidylinositol 3-kinase (PI3K) signaling cascades [20-23]. A member of the IRS family is IRS-1. IRS-1 mRNA is expressed in the cerebral cortex [24] and its null mutation retards brain growth and reduces brain weight, presumably by impairing IGF-1 actions on brain growth $[25,26]$. IRS-1 might then be involved in promoting the precise and progressive addition of barrel neuropil following IGF-1 binding to its receptor. Hence, by combining succinic dehydrogenase (SDH) histochemistry and image analyses, we evaluated whether adult wild type (wt) mice and those carrying null mutations of the IRS-1 gene (IRS-1ko mice) displayed differences in barrel size.

\section{MATERIALS AND METHODS}

\subsection{Mice}

Studies were performed in genotyped adult male wild type $(n=3)$ and homozygous IRS-1 ko mice $(n=4)$ generously provided by Dr. C. Ronald Kahn (Joslin Diabetes Center and Department of Medicine, Harvard Medical School, Boston, MA). Upon arrival, mice were kept until the day of sacrifice under 12:12 hours light/dark cycle at $22^{\circ} \mathrm{C}$ having free access to food and water. Animal handling and procedures followed the guidelines of the NIH guide for the care and use of experimental animals and were approved by the institutional review committee at the University of North Carolina (UNC), Chapel Hill.

\subsection{Histological Procedures}

The anesthetized (ketamine/xylazine; 900/20 $\mu$ g/gr body weight) mice were perfused with physiological saline followed by $10 \%$ glycerol. Brains were removed and weighed and the cerebral cortex was dissected and frozen flattened [13]. Serial tangential sections $(30 \mu \mathrm{m})$ were cut in a cryostat and stained for the activity of the oxidative enzyme, succinic dehydrogenase (SDH) by means of SDH histochemistry [13]. Briefly, sections were dried on the slides at $37^{\circ} \mathrm{C}$ for 30 min; fixed in $10 \%$ formalin, $\mathrm{pH}$ 7.6, at $4^{\circ} \mathrm{C}$ for $1 \mathrm{~min}$ and rinsed in distilled water. Then they were stained by reacting them with $0.05 \mathrm{M}$ sodium succinate and $0.55 \mathrm{mM}$ nitroblue tetrazolium in $0.05 \mathrm{M}$ phosphate buffer, $\mathrm{pH}$ 7.6. Slides were rinsed and coverslipped with DPX. Animal perfusion and sample staining were carried out at UNC.

\subsection{Estimation of Barrel Cross-Sectional and Posteromedial Barrel Subfield Areas}

As previously commented, S1 barrels in the mouse brain represent collections of mechanosensory receptors located along the body. The body has different segments though. Barrels are then segregated into distinct body representations. From these representations, the most conspicuous is that known as the posteromedial barrel subfield (PMBSF) in which each PMBSF barrel represents each facial vibrissae. The histological material obtained from wt and IRS-1 ko mice was transferred to the Universidad Nacional Autónoma de México where morphometry of PMBSF barrels was conducted. Two dimensional maps of PMBSF were drawn under bright field microscope equipped with a camera lucida. Completed maps were digitized and PMBSF and barrel cross-sectional areas were estimated using Image-Pro (Media Cybernetics, Silver Spring, MD), as described elsewhere [13].

\subsection{Data Analyses}

Data are reported as means \pm standard deviation for both experimental groups. PMBSF barrel area and barrel cross-sectional area were statistically compared between wt and IRS-1 ko mice by using One-way ANOVA test followed by a Tukey's post hoc test (OriginPro v 7; OriginLab Corporation) setting the significance value at $\mathrm{p}<0.05$.

\section{RESULTS}

The number, shape and anatomical definition of the PMBSF were fully comparable between wt and IRS-1 ko mice (Figure 1). Although average barrel area (wt: 0.04761 \pm 0.00256 versus IRS- 1 ko: $0.04481 \pm 0.00076$ both in $\mathrm{cm}^{2}$ ), total barrel field area (wt: $1.5233 \pm 0.08172$ versus IRS-1 ko: $1.4673 \pm 0.03872$ both in $\mathrm{cm}^{2}$ ) and PMBSF area (wt: $1.8645 \pm 0.16628$ versus IRS-1 ko: $1.6626 \pm$ 0.04809 both in $\mathrm{cm}^{2}$ ) tended to be reduced in IRS-1 ko mice, such trends were not statistically significant. 


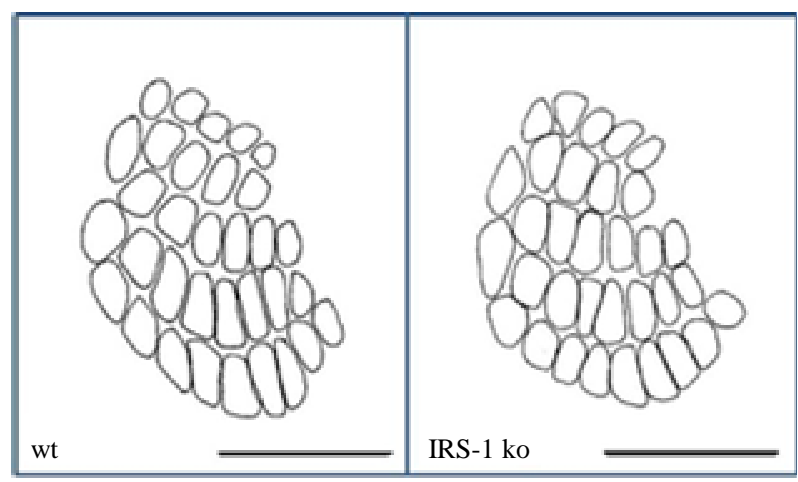

Figure 1. Representative camera lucida drawings of the barrel field of wild type (wt) and IRS-1 knock out (IRS-1 ko) mice. No qualitative differences were observed between mouse groups (Scale $=1 \mathrm{~mm})$.

\section{DISCUSSION}

Previous reports in rodents support that barrel circuitry in S1 builds up following constructivist principles [10-13, 15]. We have shown that the precise and progressive addition of barrel neuropil is promoted by IGF-1 $[15,16]$. The signaling cascade involved in this event has not been elucidated. We then explored the contribution of IRS-1 in this process by comparing the adult size of SI barrels between wt and IRS-1 ko mice. IRS-1 has been previously shown to be expressed in the cerebral cortex [24] and its mutation retards brain growth and reduces brain weight $[25,26]$. Unexpectedly, IRS-1 ko mice displayed barrel and PMBSF areas fully comparable to those observed in wt mice, thus supporting that IRS-1 is not essential for promoting the precise addition of barrel neuropil. In a previous report, Ye et al. [26] have shown that IRS-2 and IRS-4 may compensate the lack of IRS-1 with regard to myelination processes, and it is therefore conceivable that either one or both could also "rescue" the barrel's phenotype in IRS-1 ko mice. In sum, IRS-1 does not seem to mediate the trophic effects of IGF1 on the barrel cortex. Future experiments must address whether IRS-2 and/or IRS-4 participate in the construction of barrel neuropil.

\section{ACKNOWLEDGEMENTS}

Authors thank Jesús Ramirez Santos, Ivonne Mora, Edel Pineda Lopez and Raymundo Reyes for technical assistance. This work was supported in part by CONACyT (Grant No. 82879 to G. G. O.), PAPIITUNAM (Grants Nos. IN203912-3 to G. G. O. and IA202013-2 to E. U. Q.), CIC-UMSNH (Grant No. 8.37 to A. L. F. F.).

\section{REFERENCES}

[1] Bennet, M.R., Gibson, W.G. and Lemon, G. (2002) Neuronal cell death, nerve growth factor and neurotrophic models: 50 years on. Autonomic Neuroscience: Basic \&
Clinical, 95, 1-23. http://dx.doi.org/10.1016/S1566-0702(01)00358-7

[2] Blankenship, A.G. and Feller, M.B. (2010) Mechanisms underlying spontaneous patterned activity in developing neural circuits. Nature Reviews Neuroscience, 11, 18-29. http://dx.doi.org/10.1038/nrn2759

[3] Buss, R.R., Sun, W. and Oppenheim, R.W. (2006) Adaptive roles of programmed cell death during nervous system development. Annual Review of Neuroscience, 29, 1-35.

http://dx.doi.org/10.1146/annurev.neuro.29.051605.11280 $\underline{0}$

[4] Zweifel, L.S., Kuruvilla, R. and Ginty, D.D. (2005) Functions and mechanisms of retrograde neurotrophin signalling. Nature Reviews Neuroscience, 6, 615-625. http://dx.doi.org/10.1038/nrn1727

[5] Konstantinidou, A.D., Silos-Santiago, I., Flaris, N. and Snider, W.D. (1995) Development of the primary afferent projection in human spinal cord. Journal of Comparative Neurology, 354, 11-12. http://dx.doi.org/10.1002/cne.903540102

[6] Silos-Santiago, I., Jeng, B. and Snider, W.D. (1995) Sensory afferents show appropriate somatotopy at the earliest stage of projection to dorsal horn. Neuroreport, 6, 861865. http://dx.doi.org/10.1097/00001756-199504190-00009

[7] Pomeroy, S.L., LaMantia, A.S. and Purves, D. (1990) Postnatal construction of neural circuitry in the mouse olfactory bulb. Journal of Neuroscience, 10, 1952-1966.

[8] Valle-Leija, P., Blanco-Hernández, E., Drucker-Colín, R., Gutiérrez-Ospina, G. and Vidaltamayo, R. (2012) Supernumerary formation of olfactory glomeruli induced by chronic odorant exposure: A constructivist expression of neural plasticity. PloS ONE, 7, e35358.

http://dx.doi.org/10.1371/journal.pone.0035358

[9] Crowley, J.C. and Katz, L.C. (2002) Ocular dominance development revisited. Current Opinion in Neurobiology, 12, 104-109. http://dx.doi.org/10.1016/S0959-4388(02)00297-0

[10] Agmon, A., Yang, L.T., O’Dowd, D.K. and Jones, E.G. (1993) Organized growth of thalamocortical axons from the deep tier of terminations into layer IV of developing mouse barrel cortex. Journal of Neuroscience, 13, 53655382.

[11] Uribe-Querol, E., Martínez-Martínez, E., Hernández, L.R., Padilla Cortés, P., Merchant-Larios, H. and, Gutiérrez-Ospina, G. (2013) Selective and constructive mechanisms contribute to neural circuit formation in the barrel cortex of the developing rat. Advances in Bioscience and Biotechnology, 4, 785-797. http://dx.doi.org/10.4236/abb.2013.47103

[12] Catalano, S.M., Robertson, R.T. and Killackey, H.P. (1996) Individual axon morphology and thalamocortical topography in developing rat somatosensory cortex. Journal of Comparative Neurology, 367, 36-53. http://dx.doi.org/10.1002/(SICI)1096-9861(19960325)36 7:1<36::AID-CNE4>3.0.CO;2-K

[13] Riddle, D., Richards, A., Zsuppan, F. and Purves, D. (1992) Growth of the rat somatic sensory cortex and its 
constituent parts during postnatal development. Journal of Neuroscience, 12, 3509-3524.

[14] Rebsam, A., Seif, I. and Gaspar, P. (2005) Dissociating barrel development and lesion-induced plasticity in the mouse somatosensory cortex. Journal of Neuroscience, 25, 706-710. http://dx.doi.org/10.1523/JNEUROSCI.4191-04.2005

[15] Gutiérrez-Ospina, G., Calikoglu, A.S., Ye, P., D’Ercole and A.J. (1996) In vivo effects of insulin-like growth factor-I on the development of sensory pathways: analysis of the primary somatic sensory cortex (S1) of transgenic mice. Endocrinology, 137, 5484-5492. http://dx.doi.org/10.1210/en.137.12.5484

[16] Gutiérrez-Ospina, G., Uribe-Querol, E., Sánchez, N., Geovannini, H., Padilla, P. and Hernández-Echeagaray, E. (2004) Similar synapse density in layer IV columns of the primary somatosensory cortex of transgenic mice with different brain size: Implications for mechanisms underlying the differential allocation of cortical space. Brain Behavior and Evolution, 64, 61-69. http://dx.doi.org/10.1159/000079116

[17] Quartz, S.R. and Sejnowski, T.J. (1997) The neural basis of cognitive development: A constructivist manifesto. The Behavioral and Brain Sciences, 20, 537-596. http://dx.doi.org/10.1017/S0140525X97001581

[18] Hodge, R.D., D’Ercole, A.J. and O’Kusky, J.R. (2005) Increased expression of insulin-like growth factor-I (IGFI) during embryonic development produces neocortical overgrowth with differentially greater effects on specific cytoarchitectonic areas and cortical layers. Developmental Brain Research, 154, 227-237. http://dx.doi.org/10.1016/j.devbrainres.2004.10.016

[19] López-Bendito, G. and Molnár, Z. (2003) Thalamocortical development: How are we going to get there? Nature Reviews Neuroscience, 4, 276-289. http://dx.doi.org/10.1038/nrn1075
[20] White, M.F. (1997) The insulin signallling system and the IRS proteins. Diabetologia, 40, S2-S17. http://dx.doi.org/10.1007/s001250051387

[21] Mardilovich, K., Pankratz, S.L. and Shaw, L.M. (2009) Expression and functions of the insulin receptor substrate proteins in cancer. Cell Communication and Signaling, 7, 14. http://dx.doi.org/10.1186/1478-811X-7-14

[22] Withers, D.J. (2001) Insulin receptor substrate proteins and neuroendocrine function. Biochemical Society Transactions, 29, 525-529. http://dx.doi.org/10.1042/BST0290525

[23] Giovannone, B., Scaldaferre, M.L., Federici, M., Porzio, O., Lauro, D., Fusco, A., Sbraccia, P., Borboni, P., Lauro, R. and Sesti, G. (2000) Insulin receptor substrate (IRS) transduction system: Distinct and overlapping signaling potential. Diabetes/Metabolism: Research and Reviews, 16, 434-441.

http://dx.doi.org/10.1002/1520-7560(2000)9999:9999<:: AID-DMRR159>3.0.CO;2-8

[24] Folli, F., Bonfanti, L., Renard, E., Kahn, C.R. and Merighi, A. (1994) Insulin receptor substrate-1 (IRS-1) distribution in the rat central nervous system. Journal of Neuroscience, 14, 6412-6422.

[25] Pete, G., Fuller, C.R., Oldham, J.M., Smith, D.R., D’Ercole, A.J., et al. (1999) Postnatal growth responses to insulin-like growth factor I in insulin receptor substrate1-deficient mice. Endocrinology, 140, 5478-5487. http://dx.doi.org/10.1210/en.140.12.5478

[26] Ye, P., Li, L., Lund, P.K. and D’Ercole, A.J. (2002) Deficient expression of insulin receptor substrate-1 (IRS-1) fails to block insulin-like growth factor-I (IGF-I) stimulation of brain growth and myelination. Developmental Brain Research, 136, 111-121. http://dx.doi.org/10.1016/S0165-3806(02)00355-3 